\title{
Predictors of Adolescent Motherhood in Romania
}

\author{
Ecaterina Stativa ${ }^{1}$, Adrian V. Rus ${ }^{2 *}$, Valeria Filip ${ }^{3}$, Nicolae Suciu ${ }^{1,4}$, Alma \\ Stefanescu ${ }^{1}$, Jacquelyn S. Pennings ${ }^{5}$, Sheri R. Parris ${ }^{6}$, Delilah Joiner ${ }^{7}$, Silvia
}

M. Stoicescu ${ }^{4}$

${ }^{1}$ The National Institute for Mother and Child Health "Alessandrescu-Rusescu", 120 Bd. Lacul Tei 120, 020395 Bucharest, Romania
2 Southwestern Christian University, Department of Social and Behavioral Sciences, 7210 NW 39th
Expressway, Bethany, Oklahoma 73008-0340, USA
${ }^{3}$ Medicine and Pharmacy University of Oradea, Romania, 1 Universității Street, 410087 Oradea, Romania
${ }^{4}$ University of Medicine and Pharmacy "Carol Davila" Bucharest, 37 Dionisie Lupu Street, 020021 Bucharest, Romania
${ }^{5}$ Elite Research, LLC, 9901 Valley Ranch Pkwy E \#2035, Irving, Irving, Texas 75063, USA
${ }^{6}$ Texas Christian University, Karyn Purvis Institute of Child Development, 2901 W. Lowden Rees-Jones Hall, Suite 314, Fort Worth,
Texas 76129, USA
${ }^{7}$ Southern Nazarene University, Family Studies and Gerontology, School of Professional Studies, 6729 NW 39th Expressway,
Bethany, Oklahoma 73008, USA

ABSTRACT

Adolescent mother

Adult mother

Teenage pregnancy

Adolescent pregnancy

Romania

The objective of the present study was to explore what demographic and socioeconomic factors were associated with adolescent (younger than 20 years) and adult mothers living in Romania. In total, 274 adolescent and adult mothers were recruited from two maternity wards Romanian maternity wards. The mean age of the sample was 24.64 years $(S D=6.907$, range: $13-44$ years $)$. Independent samples t-tests, Pearson's chi square, Cramer's V, and risk ratios were used to assess differences in continuous and categorical demographics variables between adolescent and adult mothers. This study has shown that maternity among adolescent mothers younger than 20 years has broad sociodemographic determinations, and, consequently, the socio-economic implications could be long-term as well as costly.

\footnotetext{
*Contact address: adrian.rus@swcu.edu | adrian.rus@protonmail.com (A. V. Rus)
} 


\section{Teenage motherhood as a public health issue}

Teen pregnancy and parenting bring substantial social and economic costs through immediate and long-term influences on teen parents and their children. Thus, governments have become more interested in this phenomenon due to increased resources which need to be invested in teenage parents and their children. For instance, in US the cost of health and foster care for children of teen parents, as well as the cost of incarceration of teens parents and decrease revenue due to lower educational attainment and income among teen mothers reaches about $\$ 9.4$ billion per year (Centers for Disease Control and Prevention 2017). Additionally, in the US only about 50\% of teenage mothers will receive a high school diploma by 22 years of age (Centers for Disease Control and Prevention 2017) which makes it very difficult that for teen mothers to find employment as qualified professionals. The teenage pregnancy rate could be related, particularly in poor and developing countries, to insufficient years spent in the educational system; various social norms which discriminate against girls and women in general; or the existence of unnecessary barriers that affect access to sexual health services for teenagers without parental consent (World Health Organization 2011). In addition, teenage mothers, especially unmarried ones, get less support from their families and friends during prenatal and postpartum, and the mental stress can affect their mental health and pregnancy to a great extent (Fraser, Brockert, and Ward 1995).

Although the teenage pregnancy and motherhood is seen as a public health issue (Robson and Berthoud 2003), there is little evidence suggesting that teen pregnancy is a risk for mothers' and their children's health (Lawlor and Shaw 2002), especially if it occurs between 15-19 years of age, but nor earlier. Additionally, there are risk factors (e.g., family structure, educational, psychosocial, service accessibility) that could influence teenagers and adolescents' pregnancies, but they are not related with mothers' age (Hobcraft and Kiernan 2001; Imamura et al. 2006). However, the prevalence of preterm births (attributed to inadequate nutrition, body weight, and height), as well as 
the handicaps associated with them, are more common in babies born to teenage mothers (Imamura et al. 2007). In addition, many teenage mothers experience pregnancy difficulties, expressed by anaemia, pregnancy-induced hypertension, and intrauterine growth retardation more frequently than the norm for other women (Cunnington 2001). Furthermore, teenage mothers have increased risks for neonatal death and poor future pregnancy prognostics (Markovitz, Cook, Flick, and Leet 2005) and poor later cognitive development for mother and child (Hobcraft and Kiernan 2001; Imamura et al. 2007; World Health Organization 2011). These adverse outcomes could be also explained by the fact that the teenage mothers experience poverty and deprivation of all kinds, accompanied by various risk behaviors such as smoking (Hobcraft and Kiernan 2001; Imamura et al. 2007). Unfortunately, the negative effects are also seen in the children of teenage mothers, who were shown to be more likely to have lower school achievement, drop out of high school, and have more health problems. Additionally, they will be more likely to be incarcerated at some time during adolescence, give birth as teenagers, or experience unemployment as future young adults (Centers for Disease Control and Prevention 2017).

The legitimate question is whether aforementioned the adverse outcomes are related solely to maternal age, or if there are other factors that could lead to negative outcomes for teenage mothers and their children. It has been shown that the age of adolescent mothers, when isolated from other cultural and socioeconomic factors, can be considered a risk factor for adverse pregnancy outcomes (Fraser, Brockert, and Ward 1995), while others have shown that chronological age alone cannot be a good predictor of pregnancy outcomes, and adolescent mothers remain a high risk group due demographic characteristics of social disadvantage that are common among them (e.g., biological immaturity, inadequate prenatal care, poverty, minority status, low maternal weight before pregnancy etc.; Lee, Suhng, Lu, and Chou 1998; Scholl, Hediger, Huang, Johnson, Smith, and Ances 1992). 


\section{Teenage motherhood in Romania and European Union}

In Romania, the percentage of adolescent mothers (mothers who gave birth to their children under the age of 20 years) has fluctuated in recent years between $10 \%$ and 13\%, and in 2015 was 9.9\% (National Institute of Statistics 2015). Within the context of European Union (EU) countries (EU28), Romania is listed among the first two countries with the largest rates of births among teenagers (number of births per 1,000 women ages 15-19 and 15 -17 years). Specifically, across the EU28 in 2012 (Office for National Statistics 2014), the live birth rate (per 1,000) to women aged 15-19 was lowest in Denmark (4.4), Slovenia (4.5) and the Netherlands (4.5). At the other end, the highest birth rates were in Romania and Bulgaria at 39.4 and 42.6 live birth rate (per 1,000) to women aged 15-19, respectively (Office for National Statistics 2014). In other words, according to these evaluations (Office for National Statistics 2014), the live birth rate in 2012 (per 1,000 women) among teenagers (ages 1519) in Romania was more than 3 times higher (39.4) than the EU average (12.5). In recent European statistics, births to those under 15 years are not mentioned, probably because such events are rare, but in Romania their prevalence is $4 \%$ of all births (National Institute of Statistics 2012).

Interestingly, at the European Union level, higher birth rates among teenage women do not necessarily characterize developing countries. For instance, until the accession of Romania and Bulgaria to the EU, the United Kingdom (UK) held first place in the EU in terms of the live birth rate among teenagers between 15-19 years, having in 2006 a rate of 26.5 births per 1,000 teenage women, compared with the European average of 15 births per 1,000 teenage women (Office for National Statistics 2014; Lawlor and Shaw 2004). It is noted that, by 2012, the UK rate had dropped, reaching 14 live births per 1,000 teenage women ages 15-19 (Office for National Statistics 2014; Robson and Berthoud 2003). 


\section{Purpose and research question of the current study}

Although the birth-rate among Romanian teenagers has a relatively high prevalence (National Institute of Statistics 2015; Office for National Statistics 2014), little research has been devoted to this phenomenon, although consequences are visible in the everyday practice of professionals. Consequently, there is little systematic information about these mothers. Undoubtedly, there is a real need for monitoring of this phenomenon and adopting new socio-economic policies regarding it, and this can be done only after we know more about the demographic and socio-economic predictors of teenage birth.

The objective of the present study was to explore what demographic and socio-economic factors were associated with adolescent mothers younger than 20 years (i.e., domicile, county, ethnicity, marital status, marital status of the parents, education, qualification, socio-economic status, if the pregnancy was planned/wanted or not, recommended number of prenatal visits, if mother lived with the partner during pregnancy, smoking during last 30 days, use of contraceptives, age of the husband or partners, number of people living in the house during pregnancy, and number of rooms in the home). The purpose of our approach was to identify such factors and could be used in the future to aid public health efforts in Romania.

\section{Method}

Written consent was obtained before the study began from all participants and from The National Institute for Mother and Child Health "AlessandrescuRusescu", Bucharest, Romania. This institution is under the authority of the Ministry of Health and its Board of Ethics and the Scientific Council approved the use of the data. 


\section{Participants and sampling procedure}

In the present study, 274 mothers were recruited from two maternity wards, one placed in Bucharest (Bucharest-Ilfov County), the capital of Romania, and named the National Institute for Mother and Child Health "AlessandrescuRusescu", and the other one located in Oradea (capital of Bihor County), belonging to the Bihor County Emergency Hospital. The mean age of the sample was 24.64 years $(S D=6.907$, range: $13-44$ years $)$. The data were collected during the second half of 2014, for five months in Bucharest and three months in Oradea.

The maternity ward located in Bucharest is a unit of local and national interest, being classified as level III, and having the highest level of competence. In 2014, at this maternity ward there were recorded 3,027 births, representing $17 \%$ of the total births documented in Bucharest (Ministry of Health \& National Institute of Public Health 2014). During the time when data for this study was collected, there were 1,396 births documented, out of which $98(7 \%)$ were births of mothers under 20 years of age. In Oradea maternity ward, there were registered 3,900 births in 2014, representing 70\% of the total number of births in the Bihor County. It is also being classified as a level III medical institution (Ministry of Health \& National Institute of Public Health 2014). During the time when data was collected at Oradea maternity ward, there were recorded 926 births, out of which 148 (16\%) were mothers under 20 years of age. Out of 2,322 births documented at both maternity wards during our data collection, $246(10.6 \%)$ children were documented as being infants of mothers under 20 years of age.

After the start of the study, all the births that occurred within the last 24 hours in both maternity wards were reported along with the age of mother. If more than one adolescent mother (13-19 years of age) delivered the baby the same day, only one adolescent mother was selected, namely the one who delivered her baby first. For each adolescent mother selected, two adult mothers (20 years or older) were also selected. For the sake of choosing adult mothers randomly, two criteria were used for selection. One of the adult 
mothers must have delivered her baby before the adolescent mother did, and the second one immediately after. If the adolescent mother delivered first during a day, the two adult mothers who delivered immediately after were selected for the study. If the adolescent mother was the last mother who delivered her baby in a day, the two adult mothers who delivered right before her were selected in the current study. This explains why the adolescent mothers are representing one third of the sample. Importantly, during the period for data collection, the frequency of adolescent mothers giving birth was 7\% in Bucharest-Ilfov County and 16\% in Bihor County. This discrepancy can be explained by the fact that Oradea maternity served urban and rural population with a historical higher percentage of documented births, and Bucharest maternity served preponderantly urban population. The data was collected by two researchers and two previously trained resident physicians.

\section{Measures}

The primary dependent measure was the age of the mothers. Age of the mothers was recorded in years and divided in two categories: 13-19 years (adolescent mother) and 20-41 years (adult mother). Adolescent mother is the mother who, regardless of childbirth parity, had not reached 20 years when her baby was born. The adult mother is the non-teenage mother who, regardless of childbirth parity, was at least twenty years old when her baby was born.

Several demographic and socio-economic variables of interest were used as categorical explanatory variables (EVs). Specifically, mothers' demographic variables included whether they lived in an urban or rural location (referred to as domicile); county of residence; ethnicity; marital status; education; qualification obtained through school/courses; and social economic status (SES). In addition, the participants were questioned regarding the marital status of their parents; if their pregnancy was planned/wanted or not; the number of prenatal visits; where the participants lived during the pregnancy; if they smoked during the last 30 days; and if they had ever used a contraceptive method. A couple of continuous 
explanatory variables were also of interest in this study such as the age of the mother's husband or partner, number of people who lived in the house with the mother, number of rooms of mother's home, or age when mother's own mother had her first child.

Location was coded as urban or rural and the county of residence of participants was either Bucharest-Ilfov or Bihor. Mother ethnicity was coded as Romanian or other (including Hungarian, Rroma, or Slovak). Marital status was coded as married or not married (including divorced, separated, widowed, unmarried, co-habitation, or other/unspecified). Marital status of mother's parents was coded as married or not married (including divorced, separated, widowed, unmarried, or co-habitation). Education was coded based on years of school attended: 0-8 years (no education, unfinished and/or finished primary school; unfinished and/or finished gymnasium), 9-12 years (finished and/or unfinished high and technical school), or college (13 years or more). In our analyses, 9-12 years and 13 years or more were collapsed in a new education variable of 9-13 years or more because there was a missing cell in the crosstabulations computation. Qualification referred to a professional qualification obtained through school/course and was coded as yes or no. SES was coded as low, medium, or high. To determine SES, participants were asked whether they owned 12 items: a stove, television, refrigerator, washing machine, mobile phone, current water, flush toilet, private car, and a personal computer. Participants who owned 0-3 items were classified as low SES; 4-6 items as medium SES; and 7 or more items as high SES. The pregnancy was coded as planned/wanted or unplanned/unwanted. The Romanian Ministry of Health (2008) recommends that women with no risk factors attend eight prenatal visits, so the number of prenatal visits were coded as recommended (eight or more) or less than recommended (less than eight). In addition, we measured whether the mother lived with husband/partner during her pregnancy (coded with husband/partner) or without husband/partner (including partners' family, with relatives, friends, and in a shelter). Smoking during the last 30 days was coded as yes or no. Finally, the mothers were asked if they ever used contraceptives, coded as yes or no. The frequencies 
and percentages with which each of these socio-demographic variables occurs are fully described in Table 1.

\section{Data management and statistical analysis}

All analyses, including accuracy of data coding and entry and the statistical assumptions of the tests, were conducted using SPSS version 19.0 (IBM 2010) and the R program (R Development Core Team 2015). Frequencies of missing data were assessed. For most of the variables there were no missing data. For the variables related with the age of the mother's husband/partner, number of people in house, number of rooms in the home, smoking, qualification, social economic status, participant parent's marital status, and use of contraceptives, the percentage of missing data ranged from 0.4 to $5.5 \%$. Furthermore, the highest percentage of missing data $(13.9 \%)$ was from the variable describing the number of prenatal visits. Each analysis was conducted with all available data (pairwise deletion) and no imputation was conducted due to a relatively small percentage of missing cases.

Independent samples t-tests were used to assess mean differences in continuous demographics between adolescent and adult mothers. Using $\mathrm{R}$ statistical software packages, a series of cross-tabulations with Pearson's chi square, Cramer's V (Fox and Weisberg 2011; Navarro 2015; Warnes, Bolker, Lumley, and Johnson 2015), and risk ratios (Stevenson et al. 2015) were conducted using to examine the relationship between levels within each of the categorical demographic variables and adolescent mothers.

\section{Results}

Table 1 shows the frequencies and percentages of characteristics of the entire sample as well as divided by adolescent compared to non-adolescent mothers. Overall, out of 274 participants in the current study, 93 (34\%) of the mothers were younger than 20 years old. The sample was evenly split between those mothers who lived in urban and rural locations and who had and did not 
have the recommended number of prenatal visits. Only slightly more than half of mothers were married (57\%), had 9-13 years or more of education $(58 \%)$, had a qualification (58\%), and used a contraceptive method (56\%). Most of the mothers were categorized at living in Bihor County $(71 \%)$, were Romanian (66\%), and had married parents (76\%). In addition, most mothers were characterized as having medium or high socioeconomic status $(86 \%)$, had a planned or wanted pregnancy (64\%), lived with their husbands or partners $(80 \%)$, and did not smoke during the last 30 days (78\%). Additionally, most children were born full-term (86\%).

Table 1 also displays the results of the cross tabulations with chi-square analysis which revealed that most of the demographic variables had a significant relationship with the age of the adolescent (up to 20 years old) compared to adult mothers $(p<.001)$. Mothers who were younger than 20 years old (adolescent mothers) were more likely to live in rural area, to belong to an ethnic minority (i.e., Rroma, Hungarian, or Slovak), to be unmarried, and have parents that were not married as well. In addition, adolescent mothers were more likely to be less educated (0-8 years of education), less likely to have a qualification obtained by the school/courses and were characterized by having a low or medium socioeconomic status, with an unplanned or unwanted pregnancy, and using less than recommended prenatal services. Moreover, adolescent mothers were more likely to live with other people than with their husbands or partners (they lived with their parents, with partners' family, relatives, friends, or in a shelter), were more likely to smoke during the past 30 days and were more likely to have never used contraceptives (see Table 1, "Adolescent $<20$ years" column). Also, the percentage of children who were born full-term did not differ by mother's age.

In contrast to the younger mothers, adult mothers (20 years and older) were most likely to live in an urban area, belong to the majority ethnic group (Romanian), be married, and have married parents. In addition, adult mothers were more likely to be well educated (9-13 years of education or more), to have a qualification obtained by the school/courses, to have a 
higher socioeconomic status, have a planned or wanted their pregnancy, and used the recommended number of prenatal services. Moreover, adult mothers were more likely to live with their husbands or partners, were less likely to smoke during the last 30 days, and they were more likely to use contraceptives (see Table 3 , "Non-Adolescent $>20$ years" column).

A series of independent samples t-test showed (see Table 2) that adolescent mothers had significantly younger husbands or partners than adult mothers. Furthermore, adolescent mothers lived with significantly more people in the house than adult mothers during pregnancy and lived in homes with significantly less rooms than the adult mothers. Additionally, adolescent mothers' own mothers had their first child at a younger age than the adult mothers. Interestingly, regarding babies' birth weight, children of the mothers who were younger than 20 years old did not show a significantly different weight than babies of adult mothers.

Figure 1 displays the odds ratios with 95\% confidence intervals $(\mathrm{CI})$ associated with the bivariate relationships between the demographic/socioeconomic factors and becoming an adolescent mother. Factors associated with highest odds of being an adolescent mother compared to non-adolescent mother included being unmarried ( $\mathrm{OR}=33.43,95 \% \mathrm{CI}$ $[15.78,70.83])$, not having a qualification (OR $=21.30,95 \% \mathrm{CI}[8.84,51.35])$, and not living with husband/partner (OR $=16.74,95 \% \mathrm{CI}[7.86,35.65])$, and less than 9 years of education (OR $=7.98,95 \%$ CI $[4.53,14.08])$. While these significant effects may be expected due to the younger age of adolescent mothers, several other factors were significantly associated with adolescent motherhood. These included living in a rural area $(\mathrm{OR}=3.18,95 \% \mathrm{CI}[1.88$, $5.38])$, being an ethnic minority ( $\mathrm{OR}=3.85,95 \% \mathrm{CI}[2.26,6.56])$, and low socioeconomic status (OR 4.14, 95\% CI [1.92, 8.92]), smoking (OR $=2.13,95 \%$ CI $[1.19,3.81])$, and not using contraceptives ( $\mathrm{OR}=7.08,95 \% \mathrm{CI}[4.02,12.46])$. Table 3 shows the risk of being an adolescent mother (13-19 years old) among mothers with each of the demographic and socio-economic factors listed (risk ratio). The significance of the results is similar to the odds ratios with the magnitudes being smaller for most variables. 


\section{Discussion}

Regarding the demographic and socio-economic factors associated with adolescent mothers younger than 20 years, it was found that adolescent mothers were more likely to live in rural areas, to belong to an ethnic minority, to be unmarried, to have parents that were unmarried, to be less educated (0-8 years of education), less likely to have a qualification obtained by school/courses, more likely to have a low or medium socioeconomic status, more likely to have an unplanned or unwanted pregnancy, to use less than the recommended number of prenatal services, more likely to live with other people than with their husbands or partners, more likely to smoke during the past 30 days, and be more likely to have never used contraceptives (see Table 2, "Adolescent <20 years" column; and Table 3). Interestingly, most children were born full-term and there were no statistically significant differences across mothers.

It is important to highlight that even though Hungarians are considered a minority ethnic group in Romania, it is not a social-economic disadvantaged group as it is in the Rroma community. The high proportion of Hungarian mothers in our sample $(6.6 \%)$ it is explained by the fact that this group represents $25 \%$ of overall population in Bihor county (Planul Local de Actine pentru Invatamant 2014-2016 Actualizat 2016), but only 6.5\% at the national level (National Institute of Statistics n.d.). In addition, adolescent mothers had significantly younger husbands or partners than adult mothers during pregnancy, lived in homes with significantly fewer rooms than the adult mothers, and their own mothers had their first child at a younger age than had adult mothers. In the literature it is mentioned that adolescent pregnancy is often the result of abuse or where the partner is much older. The age of adolescents' partners could be explained by a cultural custom, namely the Rroma often informally marry under the age of 18 years old, even though this is forbidden by law. The young fathers' age also suggests that left out of school after 14-15 years of age and not being supervised, adolescent boys are vulnerable for risky behaviours. 
The results of this study are consistent with some outcomes shown previously in Europe and across the globe, namely that the teenage mothers are more likely to live in rural areas (Leppälahti, Gissler, Mentula, and Heikinheimo 2013), and belong to an ethnic minority group (Berthoud 2001; Henderson, Gao, and Redshaw 2013; Schuyler Center for Analysis and Advocacy 2008). Additionally, as shown previously, they were unmarried or had parents which were not married, with less education or work qualification (Honig 2012) or had a low or medium economic status (Horgan and Kenny 2007). Speaking of relationship between early birth and later life disadvantages, as it was shown previously (Robson and Berthoud 2003), teenage motherhood increased the probability of being disadvantaged, namely being poor in later life in countries like Denmark, Netherlands, France, Germany, Portugal, UK, and Spain, as well as having poor educational credentials, being a single parent, not being in employed, or being in a family that was not in employment. Our results are also consistent with other studies showing that a teenage mother who had a pregnancy which was not planned or wanted (Honig 2012; Tripp and Viner 2005), used less than the recommended prenatal services available (Honig 2012; Stativa et al. 2014), were more likely to smoke as previously reported (Delpisheh, Brabin, and Brabin 2006), or were more likely to use less contraceptives (Chernick et al. 2015; Honig 2012).

\section{Limitations}

The major limitation is that the original study was not designed as a true experiment. Therefore, although demographic and socio-economic variables may appear to have a causal relationship with being an adolescent mother, the cross-sectional design of the study does not allow such inferences to be made. Instead, being an adolescent mother was associated with these demographic and socio-economic variables. Additionally, some of the measured factors are confounded somewhat with age (i.e., marital status, living situation, education and qualification are likely to be associated with age for all women, not just those who become mothers). For example, 
teenagers are less likely to be married in the full population so the fact that the teenage mothers are less likely to be married may realistically be because this is true in all the population.

\section{Implications}

This study has shown that maternity among adolescent mothers younger than 20 years has broad sociodemographic determinations, and, consequently, the socio-economic implications could be long-term as well as costly. Early abandonment of the school is one of the most important factors that is associated with maternity among adolescent mothers. Accordingly, both the abandonment of compulsory education and early withdrawal (around 14-15 years of age) from Romanian education system, make these mothers more vulnerable and less likely to attain well-paid and skilled professions (Matei, Georgescu, Paunescu, and Macri 2015). Although education is the main avenue that allows adults and socially and economically marginalized children to get out of poverty and be productive members of their communities (Henaire 2001), the issue of maternity among adolescent mothers is presented more as being a public health problem. It is explained by the fact that once these young mothers leave the educational system, they connect with the protection and medical systems. Thus, the motherhood prevention strategies for adolescents are explicit in the health area but not in education or child protection, and they target specific measures such as covering the need for free contraceptives for the vulnerable population at primary care or family planning centers. The Romanian government in recent years has adopted strategies to prevent this phenomenon. Specifically, the strategy for prevention of adolescent maternity highlights the importance of transversal measures that bring together educational, public health, and protection systems, but it appears that this strategy is not effective (Ministerul Sanatatii 2014). The introduction of sexual health in schools as a compulsory subject of study has been a good practice for the northern European countries for seven decades, with notable results in lowering the maternity rate in adolescents. In Romania, the sexual and reproductive health education is an 
elective high-school level class, and the students can take this class only with the written consent of their parents. Often the introduction of this subject as a required topic in school is critically perceived by some representatives of parents', church, or lawmaker representatives. Given the long-term influences of early age maternity on the lives of adolescents and their children, the reduction of this issue is going to take a long time and as happened in other successful situations, implies a common and coherent approach involving education, health, social care, and youth services (Galavotti and Green 2006; Ma 2016).

\section{References}

Berthoud, Richard. 2001. "Teenage Births to Ethnic Minority Women." Population Trends 104: 12-17.

Chernick, Lauren S., Rebecca Schnall, Tracy Higgins, Melissa S. Stockwell, Paula M. Castaño, John Santelli, and Peter S. Dayan. 2015. "Barriers to and Enablers of Contraceptive Use among Adolescent Females and Their Interest in an Emergency Department Based Intervention." Contraception 91(3): 217-25.

Cunnington, Aubrey J. 2001. "What's So Bad about Teenage Pregnancy?" BMJ Sexual \& Reproductive Health 27(1): 36-41.

Delpisheh, Ali, Loretta Brabin, and Bernard J. Brabin. 2006. "Pregnancy, Smoking and Birth Outcomes." Women's Health 2(3): 389-403. https:// doi.org/10.2217/17455057.2.3.389

Henaire, Jean "Le Droit a L'education: Entre Discours et Realites." http://www.cifedhop.org/Fr/Publications/Thematique/thematiqu e9/Henaire.pdf (retrieved April 6, 2018).

Henderson, Jane, Haiyan Gao, and Maggie Redshaw. 2013. "Experiencing Maternity Care: The Care Received and Perceptions of Women from Different Ethnic Groups." BMC Pregnancy and Childbirth 13(1): 1-14. https:// doi.org/10.1186/1471-2393-13-196

Hobcraft, John, and Kathleen Kiernan. 2001. "Childhood Poverty, Early Motherhood and Adult Social Exclusion." The British Journal of Sociology 52(3): 495-517.

Honig, Alice Sterling. 2012. "Teen Pregnancy." International Journal of Adolescence and Youth 17(4): 181-87.

https://doi.org/10.1080/02673843.2012.655912. 
Horgan, Richard P., and Louise Clare Kenny. 2007. "Management of Teenage Pregnancy." The Obstetrician \& Gynaecologist 9(3): 153-58.

IBM Corp. 2010. IBM SPSS Statistics for Windows (Version 19.0) 2010. Armonk, NY: IBM Corp.

Imamura, Mari, Janet Tucker, Phil Hannaford, Margaret Astin, Miguel Oliveira da Silva, Kitty W. M. Bloemenkap, Helle Karro, Jørn Olsen, and Marleen Temmerman. 2006. REPROSTAT 2: A Systematic Review of Factors Associated with Teenage Pregnancy in the European Union. Aberdeen, Scotland: University of Aberdeen.

Galavotti, Christine, and Diane C. Green. 2006. "England's National Teenage Pregnancy Strategy." The Lancet 368(9550): 1846-1848. https://doi.org/10.1016/S0140-6736(06)69751-1

Fraser, Alison M., John E. Brockert, and Ryk H. Ward. 1995. "Association of Young Maternal Age with Adverse Reproductive Outcomes." New England Journal of Medicine 332(17): 1113-18.

Fox, John, and Sanford Weisberg. 2011. "Multivariate Linear Models in R." An $R$ Companion to Applied Regression. Los Angeles: Thousand Oaks.

Lee, Meng Chih, Lii An Suhng, Tsung Hsueh Lu, and Ming Chih Chou. 1998. "Association of Parental Characteristics with Adverse Outcomes of Adolescent Pregnancy." Family Practice 15(4): 336-42.

Leppälahti, Suvi, Mika Gissler, Maarit Mentula, and Oskari Heikinheimo. 2013. "Is Teenage Pregnancy an Obstetric Risk in a Welfare Society? A Population-Based Study in Finland, from 2006 to 2011." BMJ open 3: e003225. https://doi.org/10.1136/bmjopen-2013-003225

Lawlor, Debbie A., and Mary Shaw. 2002. "Too Much Too Young? Teenage Pregnancy is Not a Public Health Problem." International journal of Epidemiology 31(3): 552-53.

Lawlor, Debbie A., and Mary Shaw. 2004. "Teenage Pregnancy Rates: High Compared with Where and When?" Journal of the Royal Society of Medicine 97(3): 121-23.

Ma, Richard. 2016. "England's Teenage Pregnancy Strategy Has Been a Success: Now Let's Work on the Rest." The Lancet 388(10055): 1981. https:// doi.org/10.1016/S0140-6736(16)31856-

Matei, Alina, Georgescu Ana-Maria, Paunescu Megdonia, and Macri Cecilia Veronica. 2015. "Studiu de impact privind implementarea programelor educationale de reducere a fenomenului de abandon scolar in cadrul proiectului Educatia - Sansa catre societatea cunoasterii."

http://proiecte.pmu.ro/c/document_library/get_file?p_1_id=938494 \&folderId=939007\&name=DLFE-5823.pdf (retrieved April 6, 2018) 
Markovitz, Barry P., Rebeka Cook, Louise H. Flick, and Terry L. Leet. 2005.

"Socioeconomic Factors and Adolescent Pregnancy Outcomes:

Distinctions Between Neonatal and Post-Neonatal Deaths?" BMC Public Health 5(1): 79. https:/ / doi.org/10.1186/1471-2458-5-79

Ministry of Health, The Order of 12/2004 updated by the Order of the Ministry of Health, No. 1982 of December 5th, 2008.

Ministerul Sanatatii Strategia Nationala de Sanitate 2014-20120. 2014.

http://www.ms.ro/wp-content/uploads/2016/10/Anexa-1-

Strategia-Nationala-de-Sanatate-2014-2020.pdf (retrieved April 6, 2018)

Ministry of Health, National Institute of Public Health, \& National Center for Statistics and Informatics in Public Health. 2014. "Natural Movement of the Population" [Miscarea naturala a pupulatiei], Buletin Informativ 11.

Navarro, Daniel. 2015. Learning Statistics with r: A Tutorial for Psychology Students and Other Beginners: Version 0.5. Adelaide, Australia: University of Adelaide.

National Institute of Statistics "Population." 2015. http://www.insse.ro/cms/files/Anuar\%20statistic/02/02\%20Popul atie_ro.pdf (2015), (retrieved August 3, 2015).

National Institute of Statistics "Rezultatele definitive ale Recensamantului Populatiei si al Locintelor - 2011 (Caracteristici demografice ale populatiei)." 2011. http://www.recensamantromania.ro/wpcontent/uploads/2013/07/REZULTATE-DEFINITIVE-

RPL_2011.pdf, (retrieved on April 12, 2018).

Office for National Statistics "International Comparisons of Teenage Births: ONS Analyses the Latest Teenage Birth Rates - How Does the UK Compare?" 2014. http://www.ons.gov.uk/ons/rel/vsob1/birthsby-area-of-usual-residence-of-mother--england-and-wales/2012/styinternational-comparisons-of-teenage-pregnancy.html?format=print, (retrieved August 3, 2015).

Planul Local de Actine pentru Invatamant 2014-2016 Actualizat. 2016. https://www.isjbihor.ro/download/mielut/PLAI\%20\%20BIHOR\%2 02014-2020-ACTUALIZAT-2016-05\%20decbr..pdf, (retrieved on April $12,2018)$.

Team, R. Core. 2015. "R: A Language and Environment for Statistical Computing." R Foundation for Statistical Computing.

Robson, Karen, and Richard Berthoud. 2003. "Teenage Motherhood in Europe: A Multi-Country Analysis of Socioeconomic Outcomes." European Sociological Review 19(5): 451-66. 
Scholl, Theresa O., Mary L. Hediger, Jianping Huang, Francis E. Johnson, Woollcott Smith, and Isadore G. Ances. 1992. "Young Maternal Age and Parity Influences on Pregnancy Outcome." Annals of Epidemiology 2(5): 565-575.

Schuyler Centre for Analysis and Advocacy. 2008. "Teenage Births: Outcomes for Young Parents and Their Children."

Stativa, Ecaterina, Adrian V. Rus, Nicolae Suciu, Jacquelyn S. Pennings, Max E. Butterfield, Reggies Wenyika, and Rebecca Webster. 2014. "Characteristics and Prenatal Care Utilisation of Romanian Pregnant Women." The European Journal of Contraception \& Reproductive Health Care 19(3): 220-226. https:// doi.org/10.3109/13625187.2014.907399

Stevenson, Mark, Telmo Nunes, Cord Heuer, Jonathon Marshall, Javier Sanchez, Ron Thornton, Jeno Reiczigel, Jim Robison-Cox, Paola Sebastiani, Peter Solymos, Kazuki Yoshida and Simon Firestone. 2015. "epiR: Tools for the Analysis of Epidemiological Data. R package version 0.9-62."

Tripp, John, and Russell Viner. 2005. "Sexual Health, Contraception, and Teenage Pregnancy." The BMJ 330(7491): 590-593.

WHO Early. 2012. "Early Marriages, Adolescent and Young Pregnancies." A65: 13.

https://apps.who.int/gb/ebwha/pdf_files/WHA65/A65_13-en.pdf

Warnes, Gregory R., Ben Bolker, Thomas Lumley, and Randall C. Johnson. 2015. "gmodels: Various $R$ Programming Tools for Model Fitting." $R$ package version 2, no. 3 . 
Table 1. Demographic frequencies, percentages, and comparisons between adolescent and non-adolescent mothers

\begin{tabular}{|c|c|c|c|c|c|c|c|c|c|}
\hline & \multicolumn{2}{|c|}{ Descriptives } & \multicolumn{2}{|c|}{$\begin{array}{l}\text { Non-Adolescent } \\
>20 \text { years }\end{array}$} & \multicolumn{2}{|c|}{$\begin{array}{l}\text { Adolescent } \\
<20 \text { years }\end{array}$} & \multirow[b]{2}{*}{$x^{2}$} & \multirow{2}{*}{\multicolumn{2}{|c|}{ Cramer's V }} \\
\hline & $\mathrm{n}$ & $\%$ & $\mathrm{n}$ & $\%$ & $\mathrm{n}$ & $\%$ & & & \\
\hline Mother's Domicile & & & & & & & 18.12 & $* *$ & .257 \\
\hline Urban & 139 & 50.7 & 109 & $78.4 \mathrm{a}$ & 30 & $21.6 \mathrm{a}$ & & & \\
\hline Rural & 135 & 49.3 & 72 & $53.3_{b}$ & 63 & $46.7 \mathrm{~b}$ & & & \\
\hline County & & & & & & & .43 & & .040 \\
\hline Bucharest-Ilfov & 80 & 29.2 & 50 & $62.5 \mathrm{a}$ & 30 & $37.5 \mathrm{a}$ & & & \\
\hline Bihor & 194 & 70.8 & 131 & $67.5 \mathrm{a}$ & 63 & $32.5 \mathrm{a}$ & & & \\
\hline Ethnicity & & & & & & & 24.37 & $* *$ & .298 \\
\hline Romanian & 182 & 66.4 & 139 & $76.4 \mathrm{a}$ & 43 & $23.6 \mathrm{a}$ & & & \\
\hline Other ${ }^{1}$ & 92 & 33.6 & 42 & $45.7 \mathrm{~b}$ & 50 & $54.3 \mathrm{~b}$ & & & \\
\hline Marital Status & & & & & & & 117.48 & ** & .655 \\
\hline Married & 155 & 56.6 & 145 & $93.5 \mathrm{a}$ & 10 & $6.5 \mathrm{a}$ & & & \\
\hline Not married & 119 & 43.4 & 36 & $30.3_{b}$ & 83 & $69.7 \mathrm{~b}$ & & & \\
\hline Marital status of mother's parents & & & & & & & 20.14 & $* *$ & .272 \\
\hline Married & 208 & 75.9 & 153 & $73.6_{a}$ & 55 & $26.4_{a}$ & & & \\
\hline Not married & 64 & 23.4 & 27 & $42.2 \mathrm{~b}$ & 37 & $57.8 \mathrm{~b}$ & & & \\
\hline Education & & & & & & & 55.59 & $* *$ & .450 \\
\hline $0-8$ years & 114 & 41.6 & 46 & $40.4 \mathrm{a}$ & 68 & $59.6 \mathrm{a}$ & & & \\
\hline 9-13 years or more & 160 & 58.4 & 135 & $84.4_{\mathrm{b}}$ & 25 & $15.6 \mathrm{~b}$ & & & \\
\hline Qualification & & & & & & & 68.72 & $* *$ & .504 \\
\hline Yes & 113 & 41.7 & 107 & $94.7 \mathrm{a}$ & 6 & $5.3 \mathrm{a}$ & & & \\
\hline No & 158 & 58.3 & 72 & $45.6_{b}$ & 86 & $54.4 \mathrm{~b}$ & & & \\
\hline Socio-economic status & & & & & & & 30.48 & ** & .336 \\
\hline Low & 33 & 12.0 & 15 & $45.5 \mathrm{a}$ & 18 & $54.5_{a}$ & & & \\
\hline Medium & 50 & 18.2 & 21 & $42.0_{a}$ & 29 & $58.0_{\mathrm{a}}$ & & & \\
\hline High & 187 & 68.2 & 145 & $77.5 \mathrm{~b}$ & 42 & $22.5 \mathrm{~b}$ & & & \\
\hline Pregnancy & & & & & & & 29.02 & $* *$ & .325 \\
\hline Planned/Wanted & 176 & 64.2 & 137 & $77.8_{a}$ & 39 & $22.2_{a}$ & & & \\
\hline Unplanned/Unwanted & 93 & 34.0 & 44 & $44.9 \mathrm{~b}$ & 54 & $55.1_{\mathrm{b}}$ & & & \\
\hline Prenatal visits & & & & & & & 34.56 & $* *$ & .383 \\
\hline Recommended (8 or more) & 111 & 47 & 98 & $88.3 \mathrm{a}$ & 13 & $11.7 \mathrm{a}$ & & & \\
\hline Less than recommended & 125 & 53 & 65 & $52.0 \mathrm{~b}$ & 60 & $48.0 \mathrm{~b}$ & & & \\
\hline Lived during the pregnancy & & & & & & & & & \\
\hline With husband/partner & 218 & 79.6 & 171 & $78.4_{a}$ & 47 & $21.6 \mathrm{a}$ & 70.26 & $* *$ & .506 \\
\hline Without husband/partner ${ }^{3}$ & 56 & 20.4 & 10 & $17.9 \mathrm{~b}$ & 46 & $82.1 \mathrm{~b}$ & & & \\
\hline Smoking in the last 30 days & & & & & & & 5.84 & * & .147 \\
\hline No & 211 & 77.6 & 148 & $70.1_{a}$ & 63 & $29.9 \mathrm{a}$ & & & \\
\hline Yes & 61 & 22.4 & 32 & $52.5 \mathrm{~b}$ & 29 & $47.5 \mathrm{~b}$ & & & \\
\hline Usage of contraceptives? & & & & & & & 49.18 & ** & .424 \\
\hline No & 121 & 44.3 & 52 & $43.0 \mathrm{a}$ & 69 & $57.0 \mathrm{a}$ & & & \\
\hline Yes & 152 & 55.7 & 128 & $84.2 \mathrm{~b}$ & 24 & $15.8_{\mathrm{b}}$ & & & \\
\hline The child was born full-term & & & & & & & .07 & & .016 \\
\hline No & 33 & 12.0 & 23 & $69.7 \mathrm{a}$ & 10 & $30.3_{a}$ & & & \\
\hline Yes & 236 & 86.1 & 155 & $65.7_{a}$ & 81 & $34.3_{a}$ & & & \\
\hline
\end{tabular}

Note: Descriptive percents not summing to $100 \%$ reflect missing data. ${ }^{*} \mathrm{p}<0.05 ;{ }^{* *} \mathrm{p}<0.001$. Row proportions sum to $100 \%$. Descriptive percents not summing to $100 \%$ reflect missing data. Differences are tested within demographic item using z-test of proportions with continuity correction. Proportion with different subscripts within the same block (e.g., Mother's domicile) are significantly different $(p<0.05)$. ${ }^{1}$ Other category included Hungarian, Rroma, and Slovak. ${ }^{2}$ Without husband/partner category included women that lived with their parents (without husband/partner), partners' family, relatives, friends, and in a shelter. ${ }^{r}$ Reference group for each demographic variable. 
Figure 1. Forrest plot of Odds Ratios of variables predicting adolescent (vs. nonadolescent) births. Each odds ratio represents the bivariate relationship between predictor and outcome

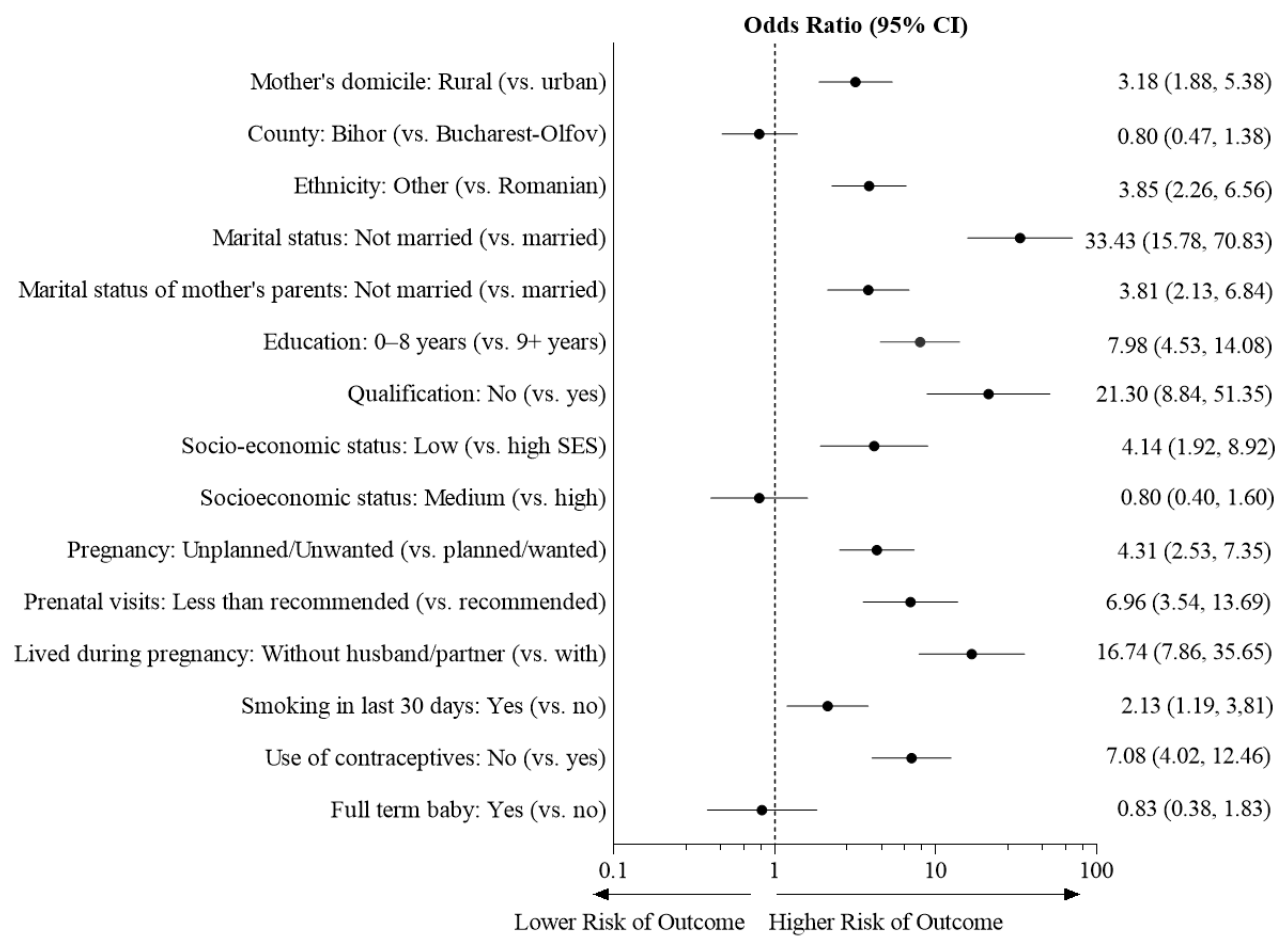

Table 2. Independent samples t-tests showing adolescent and adult mothers across several variables

\begin{tabular}{|c|c|c|c|c|c|c|c|c|c|}
\hline \multirow[b]{3}{*}{$\begin{array}{l}\text { Age of the husband or } \\
\text { partner }\end{array}$} & \multicolumn{2}{|c|}{$\begin{array}{l}\text { Non-Adolescent } \\
>20 \text { years }\end{array}$} & \multicolumn{2}{|c|}{$\begin{array}{l}\text { Adolescent } \\
<20 \text { years }\end{array}$} & \multicolumn{2}{|c|}{$\begin{array}{l}\text { Independent } \\
\text { t-test }\end{array}$} & \multirow[b]{2}{*}{$p$} & & \multirow[b]{2}{*}{$\square^{\square}$} \\
\hline & $M$ & $S D$ & $M$ & $S D$ & $d f$ & $t$ & & & \\
\hline & 31.72 & 6.01 & 21.96 & 3.62 & 257.64 & 16.52 & $<0.001$ & $* * *$ & 0.431 \\
\hline $\begin{array}{l}\text { Number of people in } \\
\text { household }\end{array}$ & 3.93 & 1.52 & 4.62 & 1.73 & 141.44 & -3.09 & 0.002 & ** & 0.039 \\
\hline Number of rooms & 2.97 & 1.58 & 2.63 & 0.99 & 235.48 & -2.09 & 0.038 & * & 0.012 \\
\hline Mother's age at first child & 21.39 & 3.98 & 18.54 & 2.85 & 141.88 & 5.68 & $<0.001$ & $* * *$ & 0.108 \\
\hline Child's birth weight & 3281.48 & 923.49 & 3194.15 & 1219.39 & 272 & 0.66 & 0.51 & & \\
\hline
\end{tabular}

Note: ${ }^{*} \mathrm{p}<0.05 ;{ }^{* *} \mathrm{p}<0.01 ;{ }^{* * *} \mathrm{p}<0.001$. 
Table 3. Demographic frequencies, percentages, relative risk, and comparisons between adolescent and non-adolescent mothers.

\begin{tabular}{lll}
\hline & $\begin{array}{l}\text { Relative } \\
\text { Risk }\end{array}$ & $\begin{array}{l}\text { Confidence } \\
\text { Interval }\end{array}$ \\
\hline & 1.47 & $(1.23,1.76)$ \\
Mother's Domicile: Rural (vs. urban) & 0.93 & $(0.76,1.13)$ \\
County: Bihor (vs. Bucharest-Ilfov) & 1.67 & $(1.32,2.12)$ \\
Ethnicity: Other' (vs. Romanian) & 3.09 & $(2.35,4.07)$ \\
Marital Status: Not married (vs. married) & 1.74 & $(1.29,2.35)$ \\
Marital status of mother's parents: Not married (vs. married) & 2.09 & $(1.66,2.64)$ \\
Education: 0-8 years (vs. 9-13 years or more) & 2.08 & $(1.74,2.48)$ \\
Qualification: No (vs. yes) & & \\
Socio-economic status: & 1.71 & $(1.16,2.50)$ \\
$\quad$ Low (vs. high) & 0.94 & $(0.77,1.14)$ \\
$\quad$ Medium (vs. high) & 1.73 & $(1.37,2.19)$ \\
Pregnancy: Unplanned/Unwanted (vs. planned/wanted) & 1.70 & $(1.42,2.04)$ \\
Prenatal visits: Less than recommended (vs. recommended [8 or more]) & 4.39 & $(2.49,7.74)$ \\
Lived during the pregnancy: Without husband/partner ${ }^{3}$ (vs. with) & 1.34 & $(1.04,1.72)$ \\
Smoking in the last 30 days: Yes (vs. no) & 0.51 & $(0.41,0.63)$ \\
Usage of contraceptives: No (vs. yes) & 0.94 & $(0.74,1.20)$ \\
The child was born full-term: Yes (vs. no) & &
\end{tabular}

